\title{
Erratum to: Quality Changes and Shelf-Life Prediction of a Fresh Fruit and Vegetable Purple Smoothie
}

\author{
Gerardo A. González-Tejedor ${ }^{1,2}$ • Ginés Benito Martínez-Hernández ${ }^{2,3}$. \\ Alberto Garre $^{1,4}$ • Jose A. Egea ${ }^{4}$ • Pablo S. Fernández ${ }^{1,3}$. \\ Francisco Artés-Hernández ${ }^{2,3}$ (i)
}

Published online: 26 August 2017

(C) Springer Science+Business Media, LLC 2017

Erratum to: Food Bioprocess Technol

$$
\text { DOI 10.1007/s11947-017-1965-5 }
$$

The original version of this article unfortunately contained mistake. The Fig. 5 image was a duplicate of Fig. 4.

Herewith, the authors would like to correct the image of Fig. 5 as shown.

The online version of the original article can be found at http://dx.doi.org/ 10.1007/s11947-017-1965-5

Francisco Artés-Hernández

fr.artes-hdez@upct.es

1 Food Safety and Preservation Group, Department of Food Engineering, Universidad Politécnica de Cartagena, Paseo Alfonso XIII, 48, 30203 Cartagena, Murcia, Spain

2 Postharvest and Refrigeration Group, Department of Food Engineering, Universidad Politécnica de Cartagena, Paseo Alfonso XIII, 48, 30203 Cartagena, Murcia, Spain

3 Institute of Plant Biotechnology, Universidad Politécnica de Cartagena, Campus Muralla del Mar, 30202 Cartagena, Murcia, Spain

4 Department of Applied Mathematics and Statistics, Universidad Politécnica de Cartagena, Av. Dr. Fleming S/N, 30202 Cartagena, Murcia, Spain 


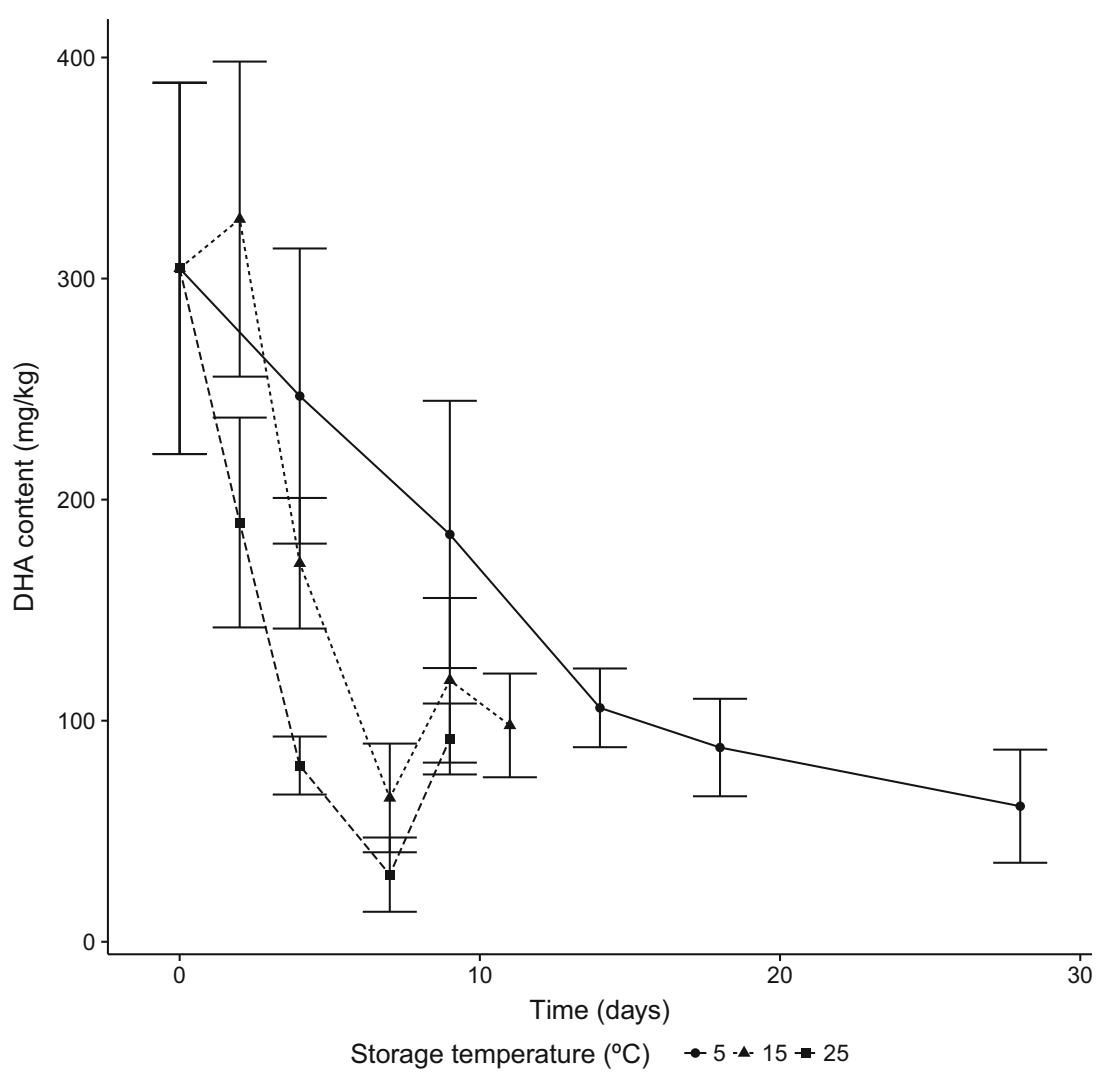

